\title{
Quality management research trends in context of Industry 4.0: A short review
}

\author{
Benjamin Rudalija ${ }^{1}$ \\ ${ }^{1}$ Mechanical Engineering, International University of Sarajevo, Bosnia and Herzegovina
}

*Corresponding author: benjamin18rudalija@gmail.com

(C) The Author

2020.

Published by

ARDA.

\begin{abstract}
With new century we have new revolution which is Industry 4.0. That industry is helping companies to create smarter products together with services in such way that companies will reduce costs and they will increase efficiency. In that operation, human factor is crucial for the application. One of the benefits of the Industry 4.0 is the Smart factory that makes a solution. "That is leading to the automated procedures. Also, it is leading to the uncomplicated setup including simple installation and sometimes very high rate of scalability. All of this feature will help companies in the manufacturing process and further optimization their own processes. In the end, it will boost up their efficiency from the aspect of manufacturing.

With digitalization of major industries, almost 5 million workplaces can be lost by 2020. In the same time, it will stop really fast the market demand for product which are produced using outdated technologies. Because of that, such production would be shut down because of higher costs and inefficiency in the first place.
\end{abstract}

Keywords: Industry 4.0, Quality management, Innovation

\section{Introduction}

Quality management is topic that is discussed in today's contemporary world. Today, we have technological dominance in our lives, and technology is in every aspect of our everyday activity. Scientists are telling even technology is helpful, but it can be dangerous. So, this problem is taken to be part of development in Quality Management in the industry 4.0. Goal of 4.0 era is to focus to unravel advancement of Quality and its implications in terms of Economics, Decision Models, Business Models, Human and Technological Perspectives etc. Some key terms are:

1) Quality Management.

2) Industry 4.0.

3) Technology.

4) Quality Culture.

5) Behavioral Aspects.

We have to know what term Industry 4.0 means. Industry 4.0 is a part, or better to say subset of fourth industrial revolution. Industrial areas which are not considered as a real industry are considered as part of Industry 4.0. Example can be smart cities, or smart cars.

Term Industry 4.0 or "fourth revolution" has machines which are working with wireless connection. Also, in those machines is a lot of sensors which are connected to the system which tracks every part of production process and making decisions by its own. So, a type of AI (Artificial Intelligence).

Industry 4.0 is using different manufacturing technologies and processes. Some of them are cyber-physical system (CPS), the internet of things (IoT), cloud computing, cognitive computing, industrial internet of things (IIOT) etc.

This work is licensed under a Creative Commons Attribution License (https://creativecommons.org/licenses/by/4.0/) that allows others (c) (i) to share and adapt the material for any purpose (even commercially), in any medium with an acknowledgement of the work's authorship and initial publication in this journal. 
So, the concept of Quality Management is very young. That concept wasn't understood before 1980's. During the 80s and 90s, concept of Quality Management became famous.

From different studies we can see that the suggest quality environment can be created in such way that everybody are inspired to have feeling that they are responsible for it. It is very important to have good Quality Cost. Poor Quality Cost can be cut through leadership emphasis, message credibility, peer involvement and employee empowerment.

Poor Quality incurs companies 5\% to $30 \%$ of their annual sales but companies with strong structured quality system spend 350 million dollars less than poorly structured quality systems.

One of the objectives is to ascertain control limits of quality to address problems like inflexibility, customization, longer supply chains.

One of the solutions is to include Statistical Quality Control Techniques, but better choice is to look for Innovative techniques.

\section{Short history of industry}

As the name is telling us, industry 4.0 is fourth type of industry in human history. But we can't talk about this industry if we don't know what happened before. Also, people can learn a lot of things based on industries before such as 1.0, 2.0 and 3.0. All those historical discoveries changed human kind forever, but time is going on. So is the industry. Pathways in industry 4.0 can be based on (some of them) the previous industries.

\section{Industry 1.0}

Importance of this industry was huge. At the end of the 18th century, steam engine is discovered. That discovery changed industry from the ground. With making steam engine, people started to use heavy machinery.

\section{Industry 2.0}

The second industry revolution is based on using the electricity. With this discovery it was possible to use a conveyor belt and assembly line.

\section{Industry 3.0}

In this industry, most important pathway was introduction of automatization of production processes using electrical energy and using information and communication technologies.

\section{Industry 4.0}

Finally, the evolution of cyber technologies and their integration into digital ecosystems along all values chains contributed to the emergence of the fourth industrial revolution called "Industry 4.0". The first concept of industry 4.0 was presented at the Industrial Technology Fair in Hanover in 2011.

Since then, many different companies started to developed solutions in line with the concept of Industry 4.0. Many governments also support the development of such solutions, especially European governments (with an emphasis on the German government), USA and Japanese government, confirming that this new industry is viewed as a strategy by major industries in the world.

In general, the main purpose of Industry 4.0 is the emergence of digital manufacturing, also referred to as "smart factory", which means smart networking, mobility, flexibility of industrial operations and their interoperability, integration with customers and suppliers, and the adoption of innovative business models.

\section{Stages of formation of Industry 4.0 and the key indicators of its development}

In this following text I'm going to provide the study of the main stages of formation related to industry 4.0. Also, main goal is to determine the key indicators of development. Important things are to analyze the process of formation of Industry 4.0 which is going to be described below. After reading the text you will be able to distinguish the main stages which are:

- Formation of industry 4.0 as a sphere of industry.

- Transition to Industry 4.0.

- Preparation of the socio-economic system.

As in every system, Industry 4.0 has some potential barriers on the path of formation at each of the stages and there must be offered recommendations for overcoming them. People developed and present the system of 
indicators which are related to monitor the formation of Industry 4.0 which basically includes target values of indicators for moving to the next stage of Industry. We can conclude also that economic system of today's world - modern economic system is in different stages of the process related to the formation of Industry 4.0. Today in the world we can see that some developed countries developed the transition of the second stage while other countries who are in transition time have just started the first stage of the process. So, talking about large scale of global economy system, Industry 4.0 should be conducted in long - term scale.

Every day our global economy is developing and in certain moment we have different trends. The same situation is with Industry 4.0. People think that actual trend in the world is developing Industry 4.0 from aspect of the global economy, but that is not a case. This development is related to the future. As it is, that development can stimulate people to achieve strategic goals from which are based in core of the Industry. Landmark in modern global economy system is development of knowledge of economy. That landmark is provided from tool called Industry 4.0. Knowledge economy is recognized as the most important and optimal type in today's economic system.

Firstly, knowledge economy is very long and complex process. Even though people want to improve the system and other things, there is a lot of obstacles on that path. Many of them are low effectiveness of the existing tools (some of them are growth vectors). This problem is real and it comes from experience. So, in other to reduce risk component of the process and process information of the knowledge economy and in the same time to increase the effectiveness due to acceleration of the economy rate and economic development, Industry 4.0 allows that. Industry will diversify these tools in other to help in development.

Second, Industry 4.0 can be viewed from the different angle. It can be viewed as a self-goal. In that manner, it will push the achievements of sustainable socio-economic development. What industry 4.0 provide is reduction of labor. Even the intellectual load on modern human will reduce. The things which have exponential growth is production and innovational development of economic system. So, this is one of the research pathways in the Industry 4.0. Different and better economic system. To achieve this, economic system must be increased by efficiency, also with reduction of resource intensity. The level of real income of population should also be increased.

Due to this reasons, concept of Industry 4.0 is large in term for high scientific and practical significance. So, this can help us to explain studying of some potential problems that may occur, possibilities and perspectives of implementation in the economic practice of today's modern socio-economic systems. The main goal of this research paper is to determine and discuss the main stages in the Industry 4.0 and also to show us main key indicators of its development at each of them.

Industry 4.0 (I4.0), even if very young in revolution, has several main pillars or categories which are very important in the future development of the revolution. Also, these main pillars will explain the research pathways inside this revolution. It should be mentioned that I4.0 is still in development; every day practically, so, some things we have but some things we don't have. So, we can say that we are still in revolution.

\section{The main pillars in Industry 4.0}

In the following text I'm going to describe some of the concepts of the I4.0. Those concepts are main bases of this industry and some of them are still in progress. Those are:

1) Big Data and Analytics.

2) Autonomous Robots.

3) Simulation.

4) Horizontal and vertical system Integration.

5) The Industrial Internet of things (IoT).

6) The cloud.

7) Additive Manufacturing.

8) Augmented Reality (AR).

9) Cyber security.

\subsection{Big data and analytics}

Concept of big data sets is affecting the decision making inside the company using large, diverse and very complex datasets. This can affect the strategy of the company. For example, if company invest in this field, big data means big things. In other words, increasing in level of data will improve the company's features like competition among other companies, it will increase productivity and most important - innovation. Big data are giving big projects to company because more opportunities are there. A lot of decision makers are giving big data projects to solve challenges in organizational levels. 
The big data can be described in several ways:

- data as a tool,

- data as an industry,

- data as a strategy.

Using framework of the Big data as a tool is described as solving traditional values or chain of values problems using existing capabilities.

Using framework of big data as an industry is actually act of using new developed software for handling big data in the future. Last, using framework of big data as a strategy is actually making new data resources by development of new models in business which are innovative.

Regarding the process of big data analytics is actually to analyze large number of datasets. Those datasets will give information about customers; mostly that information will be the trends and preferences. Datasets will also contain algorithms in case of some correlations. In sets of algorithms, those can be used also for prediction of reducing error probability [1] or big data analytics can be consisted of algorithms which are predictive - they can reduce harm before damage is done [2]. If big data can be manageable, and they can, then people will have advantages out of it. Mostly that is going to be competitive advantage to the firms which means they will have benefit in their own operations, customer experience, marketing also and etc.

Generally, I4.0 is the era of technology. With more technological changes and shifts, more companies will manage mainstream business practices. They will start to increase infrastructure development. We can conclude that big data is pushing companies in more complex aspect of their business. In the today's world, we can see increase in data that is processed and generated by machines. Big data concept takes the very big and important role in I4.0 [3].

\subsection{Autonomous robots}

Another important aspect of the Industry 4.0 is autonomous production. This type of production is powered by concept called "Internet of Things" (IoT). The idea of this concepts is to have communication between different objects, computers, devices and machines by harnessing with each other. Regarding this concept, autonomous robots are the best example.

Even if in the beginning using robots in industry looked very easy, it was not a case. Today, connecting robots to a central server, programmable logic controller or big database can be coordinated and more automated than ever before. Robots can complete tasks intelligently with minimal human input which is very important. Autonomous mobile robots (AMRs) can transport things inside the factory with avoiding obstacles, or coordinate with fleet mates, they can identify where pickups or drop-offs are needed in real time etc.

We know that almost in all aspect of the industries robots are used and they will be used in all sorts of every industry and we can't predict the moment of that change. Today we have the system "machine-to-machine" but Industry 4.0 is going beyond that scope. Some of the components of the facility which are not considered as "machines" can be connected together as well and they can be treated as "machines" like robots. Environment in which they are used is called digital ecosystem. With acceleration of Industry 4.0, the usage of the robots is also accelerating because industry requires more production, logistics, distribution and all of that can be controlled by human remotely. That remotely control is communication between human and robot. Also, during the evolution of the I4.0, some of the new robotics technologies are developed such as Kuka LBR IIWA which is doing sensitive tasks and collaborate with people too.

Robot with this system is able to learn from humans and also to check, optimize and document different tasks by help of different cloud systems [4].

\subsection{Simulation}

Simulation is very important in I4.0. It is playing an important role in production in such way that is promoting sustainable manufacturing environment in the company. Digital tools are heavily used in order to achieve certain design in the system of production. They have ability of self-configuration which means it can establish effective shop-floor management. Inside the competitive business, simulation can offer different adjustments to complex systems in such way that operations are planned. Also, simulation offers knowledge and information together with accurate estimations about certain system, which is achieved by using the engineering capacity [5]. Even the strategic plan can be done using the simulation models which can help to make dynamic plan for different production systems. In those plans, simulation will do processes in real-time which means simulation is acquired. Any system that is using simulation as a help tool can create real time optimization in every operation [6]. 


\subsection{Horizontal and vertical system integration}

There are two different systems inside the factory, Horizontal integration and Vertical integration. Vertical integration is flexible system which is inside the factory. Horizontal integration is related to integration of partners which is connected with the SCs. Network inside the industry is collecting Big Data with mission to optimize the system and system performance and also to send those data to the cloud. This connection is actually creating the framework of the smart factory. With this system, we are helping the manufacturing system to make self-organization structure and every physical object is connected with other by smart networks. In the other hand, cloud system can integrate multiple vertical partners into each other using the shared platforms which are created. All of the production and processes are tracked by members of SC [7].

\subsection{The Industrial Internet of Things (IIoT)}

Internet of Things (IoT) is actually the next technical revolution in the I4.0. IoT is able to give solution for different computations or analytics. Those calculations are related to data which are stored in cloud systems. Main purpose of the IoT is connect the Internet by collecting all of the data from physical objects inside the factory. With data collecting, computers or other devices are able to make decision about certain operations [8]. With IoT, operations in the business are more agile and also, they are integrated in the same way as achieving competition on the basis of SC is. So, we can conclude that using the IoT will be crucial in the future. It will mostly help with agility and very effective decision making in the production and other processes [9].

\subsection{The cloud}

Cloud computing or CC is bringing the different advantages in the ICT paradigm. Some of them are helping $\mathrm{SCs}$ to the automatization and integration but also there are advantages related to management and administration. That is the way of virtualizing the resource and it helps to combine the system based on clientserver. CC is including pools of many IT resources that offers storage in virtual system. Also, it offers processing capabilities in variety of virtual system by serving more than one user. Cloud computing has three different models; Saas - which stands for Software as a Service. In this computing system access depends on the purchase of the customer. Next computing is PaaS - which stands for Platform of the Service in which customers are allowed to have access to their application on the cloud (software developers mostly). Last subgroup is IaaS - which stands for Infrastructure as a Service. In this computing system, customers are offered some basic activities. One of them is storing capability. One of the best examples of Cloud system today is actually Google Drive provided by Google. Other examples are Windows Azur provided by Microsoft or BlueCloud created by IBM company [10].

\subsection{Additive manufacturing}

This field of I4.0 called Additive manufacturing is also defined as 3D modelling or printing. 3D printing is used for producing goods with different requirements provided by customers. 3D printing is very popular today because it can save a lot of time by producing limited batches or limited edition of products which means that other machines will have less stock on their process of production. Many companies today are using 3D printing to reduce the weight of the airplanes. Other materials used in this industry are titanium and other metals. One of the leading companies who are investing in 3D printing technology are Apple, Google and Motorola. Main reason of that investment is to continuous smart phone production. In 3D printing, some processes as machining and milling are completed in stages; layer by layer. That means $3 \mathrm{D}$ printing is making a lot of products using less resources [11].

\subsection{Augmented reality (AR)}

Augmented Reality (AR) is actually technology which is used for interaction that helps to establish harmony between virtual world and users. In the same time, that virtual world is used as part of the real surroundings. One of the examples of this technology are Google Glass - reality glasses. Other example is Magic Leap created in 2011. Magic Leap has ability to adjust to the human eye by converting light field angle and depth [12]. Technology like this is increasing the communication between human and the machine. Things like remoting control and visual inspection of the humans are provided virtually too using AR. If computer generated graphics and physical object are combined, it can be used in many different applications. AR is using sensors mostly in order to give users motion control on the certain tasks. 


\subsection{Cyber security}

One of the issues in the I4.0 is Cyber Security. With development of technology and together with implementation in our lives, Cyber Security can have very bad and destructive impact on the business, business environment, for example terrorist attacks. So, with development of the I4.0, people have to have some solutions or defense systems which are necessary. In this industry people can use some previous terrorist attacks and use that bad experience in order to protect people from future attacks. Even if costs of preventing the cyber war will cost the companies a lot of money, in the end, total cost is not to high if we take into account potential negative effects of the cyber war or attacks [13].

Table 1 is representation of the summary of the concepts that explain the vision of the future in Industry 4.0.

\begin{tabular}{|c|c|c|}
\hline THE CONCEPTS & $\begin{array}{l}\text { THE DEFINITIONS OF THE } \\
\text { CONCEPTS }\end{array}$ & $\begin{array}{l}\text { THE EXAMPLES OF THE } \\
\text { CONCEPTS }\end{array}$ \\
\hline BIG DATA & $\begin{array}{l}\text { Large, complex datasets that } \\
\text { affect the decision making of } \\
\text { companies }\end{array}$ & $\begin{array}{l}\text { Big data analytics, algorithms, } \\
\text { software programs }\end{array}$ \\
\hline AUTONOMOUS ROBOTS & $\begin{array}{l}\text { Solve complex tasks which cannot } \\
\text { be solved by human }\end{array}$ & $\begin{array}{l}\text { Kuka Iwaa has the learning ability } \\
\text { to achieve some certain tasks }\end{array}$ \\
\hline SIMULATION & $\begin{array}{l}\text { Mathematical modelling, } \\
\text { algorithms that optimize the } \\
\text { process }\end{array}$ & Software programs \\
\hline $\begin{array}{l}\text { HORIZONTAL\&VERTICAL } \\
\text { SYSTEM INTEGRATION }\end{array}$ & $\begin{array}{l}\text { Integration of inside of the factory } \\
\text { and } \mathrm{SC}_{5}\end{array}$ & Smart factories, cloud systems \\
\hline INTERNET OF THINGS & $\begin{array}{l}\text { Connection of the physical objects } \\
\text { and systems }\end{array}$ & Smart network \\
\hline CLOUD COMPUTING & $\begin{array}{l}\text { Shared platforms that serve to the } \\
\text { multiple users }\end{array}$ & $\begin{array}{l}\text { Google Drive, BlueCloud, } \\
\text { Windows Azur }\end{array}$ \\
\hline ADDITIVE MANUFACTURING & $\begin{array}{l}\text { 3D printing technology, } \\
\text { producing in mass customization }\end{array}$ & $\begin{array}{l}\text { 3D printers to produce smart } \\
\text { phones }\end{array}$ \\
\hline AUGMENTED REALITY & $\begin{array}{l}\text { Human-machine interaction on } \\
\text { maintanence tasks }\end{array}$ & Google Glass \\
\hline CYBER SECURITY & $\begin{array}{l}\text { Cyber attacks to business } \\
\text { environment }\end{array}$ & $\begin{array}{l}\text { National defense systems in order } \\
\text { to prevent attacks }\end{array}$ \\
\hline
\end{tabular}

Table 1. Future of Industry 4.0.

\section{Six countries leading in the fourth industrial revolution}

Industry 4.0 is slowly taking place in the world. Even if $21^{\text {st }}$ century is era of technology, not all countries all capable to take I4.0 as a new friend. Only strongly developed country can take leader place in this industry. Today in the world we have 8 of them, those are:

- Canada

- Japan

- Germany

- Australia

- Austria

- Switzerland

- USA

- China

I will shortly explain all of these examples. These 6 countries are taken from the research in 2019 . 


\section{1) Canada}

Today, Canada is $1^{\text {st }}$ country in innovation in technology. That innovative technology includes anything starting from blockchain to AI all the way to the complete digitalization. Government of Canada even trying to blockchain their own communication system. Even though Canada is taking very high place in implementation of Industry 4.0, they don't stop to "research" this field. They have a lot of opportunities for investment and another innovation in the industry 4.0 and new business.

In the list of WEF's Drivers of Production, Canada ranks a reasonable $33^{\text {rd }}$ place with the current structure of production in the country. Also, Canada is taking $7^{\text {th }}$ place as a driver of production in the list. Some people predict that Canada can pioneer the state of production in world if they take that journey slowly with a lot of time and preparation.

\section{2) Japan}

Another leading country on the WEF's list is Japan. Japan has very strong structure of production today which is interesting even if Japan doesn't have so much natural resources. Among developed countries, Japan is very strong player, especially in manufacturing and production (cars, robots, dig. equipment). As we know, everything in the nature has balance. Same situation with Japan. Even if they are very good player for I4.0, they have another problem related to social challenge - increasing in ageing of population. But new Industry can provide good solution to Japan. Solution is called "Society 5.0" which is actually trying to help and solve some problems created with implementation of Industry 4.0 technology. Society 5.0 is like older brother to Industry 4.0. Japan is building ideas which are based on idea of "monozuri". That idea is related to work ethic in Japan and also skills in the manufacturing process.

\section{3) Germany}

Japan has its own list of leading countries in implementation of I4.0. On that list, first place is taken by Germany. Germany even has its own plan and strategy for Industry 4.0. Some of those strategies are (in first place) workers, promoting of digitalization, SMES, businesses and globality. Germany has variety of products like AI, blockchain, automation and IIoT and they are trying to bring aspect of I4.0 to those fields. They created "Platform Indsutrie 4.0", which is moderator of societal and technological exchange.

\section{4) Australia}

Australia is not well positioned as one of the leading countries regarding the implementation of I4.0 (current rank is $61^{\text {st }}$ place) but Australia has great potential. On the list "Driver of production ", Australia is taking 12th place. Australia's GDP related to manufacturing sector is very low. It is less than $7 \%$ which is very low.

Even if Australia has great potential, right now, manufacturing is on very low level. But some countries recognize that Australia can be very good, so they signed an agreement with Germany. That agreement is based on collaboration between those two countries in aspect of implementing the 4.0 technologies.

\section{5) Austria}

Austria is another country in the Europe that is very strong in production. They have very similar plan of production and implementation as Germany, with Platform Industry 4.0 established in 2014. One of the main reasons why Austria is so good is that they are "forcing" interplay between different industries. That strategy showed promising because results is joining the strategies together with scalability and transferability.

Austria is setting mostly on sustainable resources and human capital and country if taking benefits from current state of production and I4.0, also from very good production future and implementation of I4.0.

\section{6) Switzerland}

Switzerland is the third country in the Europe with good implementation of Industry 4.0. This country has good position with current and especially future state of production. On the WEF's list, position is $4^{\text {th }}$ for structure and $3^{\text {rd }}$ as a driver. Switzerland also hosts the headquarters of the forum called World Economic Forum which is held in Geneva. Together with the Germany, Switzerland was very good in resisting economic downturn owe the last years, which is not the situation with some other countries. This country is also pioneer in Industry 2025 which is planning to unite the companies together in I4.0.

\section{7) USA}

In year 2014, Industrial Internet Consortium (IIC) was founded. On that consortium, more than 100 companies participated. One of them are IBM, Intel, General Electric, AT\&T, Cisco... The purpose of the 
meeting was to discuss and work on the technology of production in the future. Again, Germany took place here with participation of two companies - Siemens and Bosch. If you check the list, you will see that a lot of IT companies are included so the main focus there was talking about IoT together with the interconnection of future factories. The Industrial Internet Consortium (IIC) is almost the same as policy of Industry 4.0. The goal is to have more efficient production, some important processes should be optimized. Also, idea is to have higher availability for the machines. The last important topic was to have high level of individualized production in the production system.

\section{8) China}

According to China and their government, they are planning to build the new system of production. That system is based on the omnipresent information and communication system.

They made plan called "Advanced Manufacturing Technology Roadmap". That roadmap has each step written down until 2050. Also, plan includes milestones for 2020 and 2030. Main goal of China's industry is to get less dependent on the products which are imported. Also, they plan to help different technologies which are related for the production. One of those production systems is automotive sector. "Advances Manufacturing Equipment" is another plan with the highest priority and it has strategy of five-year

\section{Conclusions}

With new century we have new revolution which is Industry 4.0. That industry is helping companies to create smarter products together with services in such way that companies will reduce costs and they will increase efficiency. In that operation, human factor is crucial for the application. One of the benefits of the Industry 4.0 is the Smart factory that makes a solution. That is leading to the automated procedures. Also, it is leading to the uncomplicated setup including simple installation and sometimes very high rate of scalability. All of this feature will help companies in the manufacturing process and further optimization their own processes. In the end, it will boost up their efficiency from the aspect of manufacturing.

With digitalization of major industries, almost 5 million workplaces can be lost by 2020. In the same time, it will stop really fast the market demand for product which are produced using outdated technologies. Because of that, such production would be shut down because of higher costs and inefficiency in the first place.

At the end of the paper, I present an interesting quote: "The factory of the future will have two employees: a human and a dog. The task of the human will be to feed the dog. The dog will have the task to dissuade the human to touch the automated systems." (Warren G. Bennis)

\section{References}

[1] W. Ji, L. Wang, "Big data analytics-based fault prediction for shop floor scheduling. Journal of Manufacturing Systems", Vol. 43, pp. 187-194, 2017.

[2] P. Seele, "Predictive Sustainability Control: A review assessing the potential to transfer big data driven "predictive policing" to corporate sustainability management", Journal of Cleaner Production, Vol. 153, pp. 673-686, 2017.

[3] S. Yin, O. Kaynak, "Big Data for Modern Industry: Challenges and Trends [Point of View]". Proceedings of the IEEE, Vol. 103(2), pp. 143-146, 2015.

[4] M. Aiman et al., "Industry 4.0: A review on industrial automation and robotic", Jurnal Teknologi (Sciences \& Engineering), Vol. 78, pp. 137-143, 2016.

[5] S. Weyer et al., "Future Modeling and Simulation of CPS-based Factories: An Example from the Automotive Industry", IFAC-PapersOnLine, Vol. 49(31), pp. 97-102, 2016.

[6] T. H. Uhlemann et al., "The Digital Twin: Realizing the Cyber-Physical Production System for Industry 4.0". Procedia CIRP, Vol. 61, pp. 335-340, 2017.

[7] S. Wang et al., "Towards smart factory for industry 4.0: A self-organized multi-agent system with big data based feedback and coordination”, Computer Networks, Vol. 101, pp. 158-168, 2016.

[8] H. Rahman, R. Rahmani, "Enabling distributed intelligence assisted Future Internet of Things Controller (FITC)", Applied Computing and Informatics, Vol. 14, Issue 1, pp. 73-87, 2018.

[9] P. Akhtar et al., "The Internet of Things, dynamic data and information processing capabilities, and operational agility", Technological Forecasting and Social Change, Vol. 136, pp. 307-316, 2017.

[10] K. Candel Haug et al., "Cloud adaptiveness within industry sectors - Measurement and observations", Telecommunications Policy, Vol. 40(4), pp.291-306, 2016. 
[11] W. E. Frazier, "Metal Additive Manufacturing: A Review", Journal of Materials Engineering and Performance, Vol. 23(6), pp. 1917-1928, 2014.

[12] Z. He et al., "Research on Human-computer Interaction Technology of Wearable Devices Such as Augmented Reality Supporting Grid Work", Procedia Computer Science, Vol. 107, pp. 170-175, 2017.

[13] H. S. Cho, T. H. Woo, "Cyber security in nuclear industry - Analytic study from the terror incident in nuclear power plants (NPPs)", Annals of Nuclear Energy, Vol. 99, pp. 47-53, 2017. 